\title{
REVISTAMARACANAN
}

Dossiê

\section{Poética da escavação: figurações da memória em Laura Alcoba}

\author{
Poetics of digging: figurations of memory in Laura Alcoba
}

Dayane Campos da Cunha Moura*

Universidade Federal de Juiz de Fora, Brasil

Silvina Liliana Carrizo**

Universidade Federal de Juiz de Fora, Brasil

Recebido em: 7 fev. 2019.

Aprovado em: 20 jun. 2019.

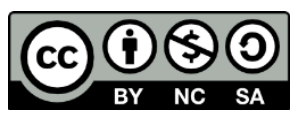

\footnotetext{
* Doutoranda em Estudos Literários pelo Programa de Pós-graduação em Letras da Universidade Federal de Juiz de Fora (UFJF). Professora de Língua Portuguesa e Espanhola no Instituto Federal de Educação, Ciência e Tecnologia do Sudeste de Minas Gerais, Campus Juiz de Fora. Mestre em Letras (Estudos Literários) e graduada em Letras, com habilitação em Espanhol, pela UFJF. (daymoura24@yahoo.com.br) CV Lattes: http://lattes.cnpq.br/9536824891677218 ORCID iD: https://orcid.org/0000-0001-6829-4103
}

** Professora Associada da Universidade Federal de Juiz de Fora, atuando na Faculdade de Letras e no Programa de Pós-graduação em Letras (Estudos Literários). Doutora e Mestre em Letras pela Universidade Federal Fluminense; graduada em Letras pela Universidad de Buenos Aires. (silvinalit@gmail.com)

CV Lattes: http://lattes.cnpq.br/1047344324398213 


\title{
Resumo
}

Este artigo propõe uma reflexão sobre a questão da memória e sua narratividade a partir da [re]criação de uma voz calcada na experiência da clandestinidade sob o olhar infantil. Trata-se de analisar o retorno à vivência do trauma, do exílio e do silenciamento que, mais de trinta anos após o Golpe Cívico-Militar argentino, encontra via de expressão na língua francesa, idioma de acolhida de Laura Alcoba. A autora, exilada na França desde o final da década de setenta, filha de militantes do grupo Montoneros, evoca, nos livros aqui analisados, tanto os meses precedentes a 1976, quanto sua descoberta a um só tempo apaixonada e angustiada do francês, o exílio, as perdas e a forte ligação com o pai, sua travessia nas línguas e narrativas.

Palavras-chave: Espaço (Auto)Biográfico. Memória. Esquecimento. Infância. Laura Alcoba.

\begin{abstract}
This article aims the reflection about memory and its narrativity from the [re] creation of a voice based on the experience of clandestinity under the childish gaze. It is about analyzing the return of the experience of the trauma, the exile and the silencing which, for more than thirty years after the Argentine Military Coup, finds a way into French language, the language token by Laura Alcoba. The author - exiled in France in the end of the seventies, daughter of Montoneros group militants - points to the months before 1976 and, at the same time, the passionate and anguished French's discovery. She also recalls the exile, the losses and the strong connection with her father, her crossing through the languages and the narratives.
\end{abstract}

Keywords: (Auto)Biographical Space. Memory. Forgetfulness. Childhood. Laura Alcoba. 
No refúgio não há epifanias.

Há silêncio.

Um silêncio oco.

O silêncio soco dos que habitam

A espera

À espera

da pergunta que nunca virá. ${ }^{1}$

Para onde foram, em tal economia, os vaga-lumes? ${ }^{2}$

Roland Barthes, em A câmara clara, procura uma foto da mãe, poucos dias após sua morte. Ele deseja encontrá-la verdadeiramente, o que o remete a Godard quando este diz: "Não uma imagem justa, justo uma imagem". A lembrança da frase de Godard é uma tentativa de afirmar que sua busca requeria mais que uma imagem. Em suas palavras, "Mas meu pesar queria uma imagem justa, uma imagem que fosse a um só tempo justiça e justeza: justo uma imagem, mas uma imagem justa". ${ }^{3}$ A imagem justa, a que fazia justiça e ao mesmo tempo se ajustava perfeitamente à sua enlutada dor não nos é revelada. O que temos é ausência: justo daquela imagem. É a falta que o leitor encontra, o vazio e as bordas conformadas pela minuciosa descrição da Foto do Jardim de Inverno. A ferida, o punctum, ${ }^{4}$ a não redução da perda a seus adereços, eis o que se dá a ler ali. Voltar-se para a própria trajetória requer um enfrentamento com múltiplas imagens no traiçoeiro espelho da memória. Como recobrar o passado, torná-lo presente, que rosto - desfigurado, segundo Paul de Man $^{5}$ - apresentar ao

\footnotetext{
1 TONUS, Leonardo. Agora vai ser assim. São Paulo: Nós, 2018, p. 14.

2 DIDI-HUBERMAN, Georges. Sobrevivência dos vaga-lumes. Trad.: Vera Casa Nova; Márcia Arbex. Belo Horizonte: Ed. UFMG, 2011, p. 96.

3 BARTHES, Roland. A câmara clara: nota sobre a fotografia. Trad.: Júlio Castañon Guimarães. Rio de Janeiro: Nova Fronteira, 2015, p. 62.

4 Barthes trabalha com duas noções centrais na fotografia: o studium, isto é, o interesse que o espectador encontra na foto, aquilo que nela agrada ou não, seu aspecto cultural histórico, social; ao studium ele opõe o punctum. Trata-se, aqui, não do que o olhar encontra, mas daquilo que sai da foto e atravessa o corpo de quem vê, como uma flecha, uma ferida, algo que punge, machuca. Cf.: Ibidem, p. 29-30.

5 Segundo De Man, à tentativa de restaurar a própria vida e recobrar um rosto, corresponderia sua inevitável decomposição, uma vez que a linguagem não pode oferecer mais que uma máscara àquilo que já está perdido, morto. O ensaio, escrito originalmente em inglês ("Autobiography As De-Facement") e publicado em 1979, poucos anos depois dos estudos de Lejeune acerca do gênero autobiográfico, foi traduzido para o espanhol e publicado em 1991 no número especial da revista Anthropos, de Barcelona. Cf.: DE MAN, Paul. La autobiografía como desfiguración. Suplemento Anthropos, Barcelona, Anthropos, n. 29, p. 113-118, 1991.
} 
leitor/espectador e outros tantos avatares que hoje circulam pelo que a pesquisadora argentina Leonor Arfuch denomina espaço biográfico? ${ }^{6}$

As imagens que passeiam pela memória, entremeadas ao esquecimento, à fabulação, ao silenciamento, como capturá-las em sua desaparição? Como falar com justiça e justeza? Inscritas sob a expressão "narrativas de si", há uma infinidade de gêneros que vão da autobiografia dita canônica, tal como descrita e, em certo sentido, prescrita por Philippe Lejeune em 0 pacto autobiográfico, ${ }^{7}$ aos vlogs, diários virtuais, entrevistas, reality shows, testemunhos, microtextos publicados em redes como Instagram, Facebook e outras, autoficção, romances autobiográficos, para citar apenas alguns exemplos. O que alguns estudiosos nomeiam como "giro subjetivo" ou "retorno do sujeito" tem início, segundo Arfuch, nos anos 70/80 do século passado, em que as grandes narrativas e os ideais da razão, do progresso, foram mais fortemente corroídos pelas recentes tragédias da humanidade, pela desconstrução da homogeneidade dos discursos que excluíam ou assimilavam as minorias. Por conseguinte, as histórias menores, as vozes antes silenciadas ou abafadas, conquistaram espaço. A subjetividade, a forma particular de vivenciar uma violência, de relatar a experiência da dor foi valorizada como algo que merecia e que urgia ser ouvido. Ao mesmo tempo, segundo a estudiosa, as fronteiras entre as esferas íntima e pública se tornaram cada vez mais tênues, movimento agudizado pelo expansivo uso das novas tecnologias. ${ }^{8}$

No caso particular da América Latina, a partir da década de 80, com a redemocratização dos países que viveram sob o jugo do Terrorismo de Estado, o testemunho e outros gêneros que conformam o espaço biográfico despertaram especial interesse tanto nas Ciências Sociais, História, Psicanálise, como nos Estudos Literários e Linguísticos. As chamadas narrativas da memória requerem, nas palavras de Arfuch, "a figura sensível da delicadeza", ${ }^{9} \mathrm{o}$ que, conforme a estudiosa, podemos alcançar na análise sob a perspectiva da "narrativa", enquanto um modo de se dispor ao texto. Vejamos:

a pesquisa a partir da narrativa requer antes de mais nada uma posição de escuta atenta: não só o quê, mas também o como do dizer, não só o "conteúdo"

\footnotetext{
6 Arfuch, em O espaço biográfico: dilemas da subjetividade contemporânea, mobiliza o conceito de Philippe Lejeune sem se limitar ao que propunha o estudioso. A pesquisadora toma como eixo a noção de "valor biográfico", elaborada por Mikail Bakhtin, para trabalhar o que denomina "espaço biográfico", entendido como um "lugar" em que circulam diferentes gêneros e hibridações, atendendo às novas formas de figuração do eu na contemporaneidade. Cf.: ARFUCH, Leonor. O espaço biográfico: dilemas da subjetividade contemporânea. Trad.: Paloma Vidal. Rio de Janeiro: EdUERJ, 2010.

7 Publicado em 1975, o livro apresenta os elementos que Lejeune então considerava essenciais para a definição do gênero "autobiografia". Em sua visão, a identidade entre autor, narrador e personagem seria imprescindível para que uma obra fosse considerada autobiográfica. Tal identidade se estabeleceria, segundo o pesquisador, através de um pacto com o leitor. Cf.: LEJEUNE, Philippe. O pacto autobiográfico. De Rousseau à internet. Org.: Jovita Maria Gerheim Noronha. Trad.: Jovita Maria Gerheim Noronha; Maria Inês Coimbra Guedes. Belo Horizonte: Ed. UFMG, 2008.

${ }^{8}$ Veja-se, a exemplo do comentário, como as redes sociais, sobretudo Whatsapp, Facebook e Twitter, por exemplo, constituíram um importante recurso de construção da imagem dos candidatos aos cargos políticos no recente processo eleitoral no Brasil.

9 No original: "la figura sensible de la delicadeza". ARFUCH, Leonor. La vida narrada. Memoria, subjetividad y política (Poliedros - Zona de crítica) (Spanish Edition, 2018). Ebook Kindle, posição 787788.
} 
de uma história mas os modos de sua enunciação, não só o contorno de uma imagem, mas sua profundidade, seu fundo, aquilo que oculta tanto como mostra. ${ }^{10}$

Nesse sentido, ainda que saibamos das armadilhas da memória, da impossibilidade de se compor ou recompor um quadro completo, as múltiplas vozes, os gritos que não se calam precisam e podem ser ouvidos porque nos interpelam, mesmo que não tenhamos vivido a violência aludida em suas linhas e entrelinhas. É preciso escutar/olhar atentamente as feridas, buscar nossa própria imagem justa em meio ao excesso de imagens que circulam diante de nossos olhos.

Neste artigo fazemos um recorte dentro do âmbito da chamada narrativa pós-ditatorial latino-americana a partir do caso argentino, ${ }^{11}$ mais especificamente, da obra da escritora Laura Alcoba, exilada desde os dez anos na França, que em 2007 lançou Manège. Petite histoire argentine, posteriormente traduzido ao espanhol por Leopoldo Brizuela sob o título La casa de los conejos. ${ }^{12}$ Publicado como "novela argentina", isto é, como romance, encontramos em sua primeira página a dedicatória a Diana E. Teruggi, militante assassinada durante o ataque à imprensa clandestina que se ocultava sob a inocente aparência de local para criação e venda de coelhos. A modo de apresentação, a autora se dirige a Diana, tratando de justificar o porquê de haver se passado tanto tempo antes que finalmente pudesse encontrar palavras e, por vezes, só apontar para o silêncio da experiência vivida nos anos 70: "Você se perguntará, Diana, por que deixei passar tanto tempo sem contar essa história. Havia prometido a mim mesma fazê-lo um dia, e mais de uma vez acabei dizendo-me que ainda não era o

10 Ibidem, posição 796. No original: "la investigación desde la narrativa requiere ante todo de una posición de escucha atenta: no sólo el qué sino también el cómo del decir, no sólo el "contenido" de una historia sino los modos de su enunciación, no sólo el contorno de una imagen sino su profundidad, su fondo, aquello que oculta tanto como muestra."

11 Ao recorrermos à expressão "narrativa pós-ditatorial", estamos nos referindo à literatura que problematiza a experiência, própria ou alheia, da violência inassimilável exercida durante as Ditaduras cívico-militares, encontrando aí a origem de suas reflexões, conflitos e questionamentos. Trata-se de uma noção bastante difundida e, embora já estejamos lidando com outra temporalidade da memória, para evocar o pensamento de Arfuch (ARFUCH, Leonor. La vida narrada... Op.), vale a pena considerar o viés adotado por Idelber Avelar em seu livro Alegorias da derrota. Segundo o autor, o uso do prefixo "pós" não se restringiria a um distanciamento temporal, mas, tal como ocorre no caso de "pós-moderno", compreendido como "momento crítico e desnaturalizador do moderno", a pós-ditadura não é apenas o que se passa posteriormente, e sim a adoção de uma postura crítica e reflexiva, que olha para o presente buscando em cada "documento de cultura a barbárie que o tornou possível" (AVELAR, Idelber. Alegorias da derrota: a finção pós-ditatorial e o trabalho do luto na América Latina. Trad.: Sandro Gouveia. Belo Horizonte: Ed. UFMG, 2003, p. 27; 118). Nesse sentido, compartilhamos também das ideias de pesquisadores como Marcio Seligmann-Silva, que defende a importância da escrita/leitura capaz de cartografar as feridas ainda abertas e as cicatrizes desenhadas por corpos ausentes (SELIGMANN-SILVA, Márcio. Apresentação da questão: a literatura do trauma. In: SELIGMANN-SILVA, Márcio (org.). História, memória, literatura: o testemunho na Era das Catástrofes. Campinas, SP: Ed. Unicamp, 2003).

Importante salientar que o que se denomina como pós-ditatorial diz respeito a momentos e instâncias diversos, desde o estágio inicial do processo de redemocratização e esforço de fortalecimento dos vínculos entre sujeito e coletividade, até um quadro político de aprofundamento da democracia e das liberdades dentro do panorama liberal, com governos que implementaram políticas nacionais e populares. O momento em que Alcoba escreve e publica - a partir dos anos 2000 e mais próximo, portanto, do surgimento do movimento dos Hijos e Hijas - está marcado pela expansão de relatos que adotam o olhar dos filhos: alguns ressentidos, outros romantizando a juventude dos pais, mas, sobretudo, relatos em que se tenta entender o ininteligível, perscrutar o passado precisamente naquilo que não passa, no que persiste sem resolução possível.

12 O livro foi publicado na Argentina pela primeira vez em 2008. 
momento". ${ }^{13}$ Assim, embora não se insira no gênero autobiográfico de maneira evidente e pactuada, uma vez que é publicado como romance, lidamos com uma das formas em que a vida atravessa o texto, tessitura entremeada de vozes diversas e lacunas, como veremos ao longo da análise.

Além do primeiro livro de Alcoba, analisaremos El azul de las abejas, publicado em francês em 2013, seis anos depois de La casa de los conejos e o recém-lançado La danza de la araña (2017), ${ }^{14}$ que apresentam, cada qual a seu modo, a perspectiva da personagem Laura, que se vê envolvida numa militância a que não apreende em sua totalidade, separada primeiro do pai e posteriormente da mãe e convocada a guardar o silêncio, sopesar cada gesto, sob o iminente perigo que não se nomeia.

Antes, porém de voltarmos nosso olhar a essa vida que se escreve, trataremos de contextualizar sua voz, sem, entretanto, submeter a escrita da autora a um rótulo. Trata-se de compreender o que Arfuch chama de "temporalidades da memória", isto é, segundo a pesquisadora, "momentos em que podem ser ditas e ouvidas certas coisas". ${ }^{15}$ Nesse sentido, logo após fim da ditadura, com a instauração dos julgamentos ao Terrorismo de Estado, os ouvidos estavam prontos a escutar testemunhos dos militantes, presos políticos, exilados, que depois deram lugar a ficções, autobiografias, biografias desses mesmos protagonistas e vítimas da violência. Nesse "largo camino del decir", para usar as palavras de Arfuch, chegou também "el tiempo de los hijos", tempo de se voltar àqueles anos, de buscar pistas de quem foram seus pais, do que fizeram, do porquê terem elegido tal ou qual caminho, e, por conseguinte, as perguntas sobre os pais são também questionamentos sobre a própria subjetividade, atravessada pela violenta e rasurada história pessoal e coletiva.

Essas vozes vieram à tona sobretudo no início dos anos 2000, mais especificamente quando o então presidente Néstor Kirchner anunciou, em seu discurso do dia 24 de março de 2004 na chamada ex ESMA (Escuela de Mecánica de la Armada), ${ }^{16}$ a necessidade de políticas da memória para que as atrocidades dos anos de ditadura não fossem esquecidas ou assimiladas. Kirchner pediu perdão, em nome do Estado, pelo silêncio em que este se mantivera durante os últimos anos e se comprometeu a transformar a antiga Escola em um Museu da Memória. Desde 2008, o espaço é ocupado pelo Centro Cultural de la Memoria Haroldo Conti, ${ }^{17}$ que promove e divulga eventos culturais relacionados aos direitos humanos.

${ }^{13} \mathrm{Em}$ espanhol: "Te preguntarás, Diana, por qué dejé pasar tanto tiempo sin contar esta historia. Me había prometido hacerlo un día, y más de una vez terminé diciéndome que aún no era el momento." ALCOBA, Laura. La casa de los conejos. Trad.: Leopoldo Brizuela. Buenos Aires: Edhasa, 2014, p. 11. Todas as citações da obra da autora se farão a partir da versão em espanhol. Todas as traduções são nossas.

${ }^{14}$ Le Bleu des abeilles foi publicado em 2013 na França e em 2014 na Argentina; La danse de l'araignée foi publicado pela Gallimard em 2017 e traduzido ao espanhol por Mirta Rosenberg e Gastón Navarro, no mesmo ano.

${ }^{15}$ No original: "hay temporalidades de la memoria, momentos -una vez más- en que pueden ser dichas -y escuchadas- ciertas cosas". ARFUCH, Leonor. La vida narrada... Op. cit., posição 1748-1749.

${ }^{16}$ A ESMA foi o maior centro de tortura e desaparecimento durante a ditadura cívico-militar argentina.

17 O Centro homenageia o escritor argentino Haroldo Conti, sequestrado e desaparecido em sua casa em 5 de maio de 1976. Para conhecer melhor a história do edifício e do Centro Cultural, acessar o site: 
Em 2005, a Suprema Corte Argentina revogou, por declarar inconstitucionais, as chamadas Leis do Perdão e reabriu diversos casos de crimes contra a humanidade. ${ }^{18}$

Os coletivos Madres, Abuelas, H.I.J.O.S. e diversos outros órgãos que lutam desde o fim do Estado de Exceção em nome da Memória, Justiça e Verdade avançam em suas batalhas e inúmeros casos voltam à tona, filhos de desaparecidos, filhos de repressores, outros familiares podem falar porque há ouvidos para ouvir. ${ }^{19}$ Todos esses passos e outros não mencionados aqui constroem a temporalidade a que Arfuch se refere - "el tiempo de los hijos": tempo de trilhar o caminho de volta, buscando as pegadas dos pais, para então criar o próprio ritmo e pisar o presente não sem as marcas do passado, mas com os próprio pés.

A partir dos anos 2000 muitos filhos, ${ }^{20}$ exilados ou não, publicaram livros de teor autobiográfico, alguns mais testemunhais, outros mais próximos às ficções de si e do outro, assim como tiveram lugar instalações diversas, filmes, peças teatrais e outras obras que tentam dar conta, cada qual a seu modo, do trauma, da perda, do medo, do fantasma dos corpos que não se encontram em lugar nenhum.

É importante assinalar que, conforme lembra Marcio Seligmann-Silva, em "História, memória, literatura: o testemunho na Era das Catástrofes", a palavra trauma se origina do grego e significa ferida, de modo que narrar seria reviver o choque e a violência que estão na origem da experiência traumática. Mobilizando os trabalhos de Freud, especialmente Para além do princípio do prazer, Seligmann-Silva observa ainda que a repetição é característica da não assimilação da vivência do trauma, uma vez que há um "desencontro com o real", que resiste a ser traduzido em palavras. Nesse sentido, os filhos repetem a incompreensão daquilo que viveram ao lado dos pais ou em sua ausência, muitos dos quais se mantiveram clandestinamente muito tempo antes de serem torturados, mortos ou desaparecidos.

Neste "tempo dos filhos", para retomar a expressão de Arfuch, encontramos relatos que tentam responder a questões que não são apenas suas, mas que são sobretudo subjetivas, conforme podemos ler nas palavras do narrador de $O$ espírito dos meus pais continua a subir na chuva, de Patricio Pron:

\footnotetext{
http://conti.derhuman.jus.gov.ar/areas/prensa/prensa.phphttp://conti.derhuman.jus.gov.ar/areas/prens a/prensa.php.

18 Trata-se da "Ley de Punto Final", de 1986, que estabelecia um prazo (60 dias a partir de sua promulgação) para a apresentação e posterior julgamento de crimes relacionados à ditadura cívico-militar e a "Ley de Obediencia Debida", sancionada em 1987. Com esta lei, os crimes cometidos por militares sob comando de um superior não poderiam ser punidos, tendo em vista que se tratava de obedecer às ordens.

${ }^{19}$ H.I.J.O.S - Hijos e Hijas por la Identidad y la Justicia contra el Olvido y el Silencio. Mais informações em: http://www.hijos-capital.org.ar/.

\begin{abstract}
20 Alguns autores cujas obras se voltam à memória pessoal marcada pela experiência do medo e desarraigo: Patricio Pron, autor de El espíritu de mis padres sigue subiendo la lluvia (2011); Andrés Neuman, autor de Una vez Argentina (2003); Ángela Raboy, autora de ¿Quién te crees que sos? (2012) e de diversos textos nos blogs Infancia y dictadura e Pedacitos de Ángela; Ernesto Semán, autor de Soy un bravo piloto de la China (2011); Félix Bruzzone, autor de Los topos (2008) e 76 (2014); Mariana Pérez, autora de Diario de una princesa montonera. 110\% verdad (2012), fruto do blog de mesmo título; Leopoldo Brizuela, autor de Una misma noche (2012); Raquel Robles, autora de Pequeños combatientes
\end{abstract} (2013); Martin Kohan, autor de Dos veces junio (2002); Fernando Araldi Oesterheld, autor de El sexo de las piedras (2014); e, claro, Laura Alcoba.
} 
Enquanto eu tentava deixar para trás as fotografias que tinha acabado de ver, compreendi, pela primeira vez que todos nós, filhos dos jovens da década de 1970, teríamos que desvendar o passado de nossos pais como se fôssemos detetives, e que nossas descobertas seriam parecidas demais com um romance policial que preferiríamos nunca ter comprado. ${ }^{21}$

Ao lado dos filhos de desaparecidos, de militantes, surgiram as vozes dos apropriados e dos filhos de repressores. ${ }^{22}$ Nesse sentido, é importante, como assinala Arfuch, dar hospitalidade às vozes que antes não puderam falar, seja por vergonha, medo ou por não encontrar ouvidos dispostos a ouvir. ${ }^{23}$ Diversos questionamentos perpassam as obras dos herdeiros da violência dos anos 70, como podemos ler na apresentação do livro Hijos de los 70, de Carolina Arenes y Astrid Pikielny:

É possível tomar distância do que fizeram os pais sem traí-los? É possível não fazê-lo sem trair a si mesmo? Quanta verdade é capaz de suportar um filho, qualquer filho, sobre seus pais? Até onde se pode incomodar com uma pergunta quando esses pais foram vítimas do pior, ou, ao contrário, quando foram acusados do pior? ${ }^{24}$

É nesse contexto que, após uma visita realizada em 2003 à casa onde vivera durante alguns meses com a mãe, Daniel e Diana, então grávida de Clara Anahí, bebê apropriada com poucos meses de vida em novembro de 1976, segundo Alcoba, "narrar se volvió imperioso":

Esse dia, estou convencida, se relaciona com uma viagem que fiz a Argentina, com minha filha, no final de 2003. Nos mesmos lugares, pesquisei, encontrei pessoas. Comecei a recordar com muito mais precisão do que antes, quando só contava com a ajuda do passado. E o tempo acabou fazendo seu trabalho mais rápido do que eu jamais poderia ter imaginado: a partir de então, narrar se tornou imperioso. ${ }^{25}$

A casa, localizada em La Plata e conhecida como "casa de la calle 30" ou simplesmente "casa de los conejos", foi recuperada em 1998 pela Asociación Anahí e convertida em Casa de la Resistencia Diana Teruggi. ${ }^{26}$ Em 2004, foi declarada Monumento Histórico Nacional e, por

21 PRON, Patricio. O espírito dos meus pais continua a subir na chuva. Trad.: Gustavo Pacheco. São Paulo: Todavia, 2018, p. 113-114.

22 Em 2017, após um erro da Suprema Corte, conhecido como "2x1", familiares de genocidas começaram a se organizar e criaram o coletivo "Historias desobedientes: familiares de genocidas por la Memoria, la Verdad y la Justicia" com vistas a se posicionar contra as atrocidades cometidas pelos seus e a finalmente saírem do silêncio em que viveram por décadas. Para saber mais sobre a formação e as ações do grupo, acessar o site: http://www.historiasdesobedientes.com/index.php.

${ }^{23}$ Cf.: ARFUCH, Leonor. La vida narrada... Op. cit., posição 1082.

${ }^{24}$ No original: "¿Es posible tomar distancia de lo que hicieron los padres sin traicionarlos? ¿Es posible no hacerlo sin traicionarse a uno mismo? ¿Cuánta verdad es capaz de soportar un hijo, cualquier hijo, sobre sus padres? ¿Hasta dónde se puede incomodar con una pregunta cuando esos padres han sido víctimas de lo peor o, por el contrario, cuando han sido acusados de lo peor?". ARENES, Carolina. Hijos de los 70: Historias de la generación que heredó la tragedia argentina (Spanish Edition, 2016). Penguin Random House Grupo Editorial Argentina. Ebook Kindle.

25 Em espanhol: "Ese día estoy convencida, se corresponde con un viaje que hice a la Argentina, en compañía de mi hija, a fines del año 2003. En los mismos lugares, yo investigué, encontré gente. Empecé a recordar con mucha más precisión que antes, cuando sólo contaba con la ayuda del pasado. Y el tiempo terminó por hacer su obra más rápidamente que lo que yo había imaginado jamás: a partir de entonces, narrar se volvió imperioso." ALCOBA, Laura. La casa de los conejos. Op. cit., p. 12.

${ }^{26}$ Daniel Mariani, esposo de Diana, não estava presente no dia do ataque, mas foi assassinado menos de um ano depois, em agosto de 1977. Sua mãe, María Isabel Chorobik de Mariani, mais conhecida como 
fim, em 2011, ressignificada como Museo Mariani-Teruggi. Ao (re)visitar a Casa em 2003, um lugar de memória por excelência, Alcoba se sente interpelada pelos destroços e tudo o que eles podem significar, assim como também por aquilo que eles não são capazes de "dizer". As marcas do passado se tornam presentes, impõem sua presença, de modo que o livro começa a ser gestado neste encontro.

Alcoba forma parte da chamada segunda geração pós-ditatorial, e mais especificamente dos "exiliados-hijos", nas palavras de Arfuch, e é a partir desse pertencimento que sua narrativa recobra o passado e lida com a herança, uma herança de toda a geração dos anos 70, não somente de quem esteve diretamente envolvido nos acontecimentos mais violentos, mas também de quem viveu os dias como se tudo estivesse como deveria estar, daqueles que preferem não questionar a própria origem, dos que questionam e se [re] descobrem outros. Ainda na apresentação de seu primeiro livro, lemos:

Vou evocar por fim toda aquela loucura argentina, todos aqueles seres arrebatados pela violência. Eu me decidi porque frequentemente penso nos mortos, mas também porque agora sei que não se pode esquecer os vivos. Mais ainda: estou convencida de que é imprescindível pensar neles. Esforçar-se por encontrar, também para eles, um lugar. ${ }^{27}$

Para um(a) leitor(a) latino-americano(a), o início desse fragmento faz ecoar notadamente a abertura do Facundo, de Sarmiento: "Sombra terrível de Facundo, vou evocarte para que, sacudindo o ensanguentado pó que cobre tuas cinzas, te ergas a explicar-nos a vida secreta e as convulsões internas que arrancam as entranhas de um nobre povo! Tu possuis o segredo: revela-nos". ${ }^{28}$ Esses ecos, essas intermitências, repercutem nas escalas que vão de uma petite histoire argentine a um relato no qual se entrelaçam experiência, subjetividade e busca pelo entendimento da história pessoal e nacional.

Encontrar lugar para os vivos, para os sobreviventes, para quem tem que lidar com a memória, com os esquecimentos, à espera, eis o ponto no qual se insere a autora. No livro, encontramos a simulação da voz infantil, a narrativa na perspectiva "da altura da menina que

"Chicha" Mariani, deu início à luta pela busca dos desaparecidos e recuperação dos netos, fundou o coletivo Abuelas de la Plaza de Mayo e participou do reencontro de inúmeras famílias. Faleceu em agosto de 2018, sem recuperar Clara Anahí. Importante assinalar que a casa se manteve tal como no dia do ataque, como uma ferida aberta a denunciar a barbárie e a confrontar o esquecimento. Para conhecer melhor a história da luta de Chicha, sugerimos dois documentários disponíveis no Youtube: Chicha Mariani, la abuela del amor (Disponível em: https://www.youtube.com/watch?v=FCTV95Oh1GQ) e Chicha Mariani, historias debidas (Disponivel em: https://www.youtube.com/watch?v=JamUuUmqXLc)

${ }^{27}$ Em espanhol: "Voy a evocar al fin toda aquella locura argentina, todos aquellos seres arrebatados por la violencia. Me he decidido, porque muy a menudo pienso em los muertos, pero también porque ahora sé que no hay que olvidarse de los vivos. Más aún: estoy convencida de que es imprescindible pensar en ellos. Esforzarse por hacerles, también a ellos, un lugar". ALCOBA, Laura. La casa de los conejos. Op. cit. 12.

${ }^{28}$ No original: "Sombra terrible de Facundo, voy a evocarte, para que, sacudiendo el ensangrentado polvo que cubre tus cenizas, te levantes a explicarnos la vida secreta i las convulsiones internas que desgarran las entrañas de un noble pueblo! Tú posees el secreto: irevélanoslo!". O livro foi publicado pela primeira vez sob o título Civilización y barbarie. Vida de Juan Facundo Quiroga y aspecto físico, costumbres y hábitos de la República Argentina, em 1845. Cf.: SARMIENTO, Domingo Faustino. Facundo ó civilización i barbarie en las pampas argentinas. 3a ed. Nova York: [s.n.], 1868. Versão digitalizada disponível em: http://www.cervantesvirtual.com/obra/facundo-o-civilizacion-i-barbarie-en-las-pampasargentinas--0/. Acesso em: 31 jan. 2018. 
fui", ${ }^{29}$ segundo Alcoba. A essa voz se interpõe em alguns momentos a da adulta que recobra e confronta o passado, conforme será possível verificar ao longo da análise, mas predomina a tentativa de capturar o olhar da menina de sete anos que vivenciou, sem entender bem, a clandestinidade e o "jogo" dos adultos.

A narrativa se inicia à maneira de um conto infantil - "Tudo começou quando minha mãe me disse: 'Agora nós também teremos uma casa com telhas vermelhas e um jardim, sabe? Como você queria. ${ }^{\prime \prime 30}$ - fora do fluxo do tempo e sem lugar preciso. Contrapondo-se a essa imagem, lemos acima "La Plata, Argentina, 1975", marcações de lugar e tempo que sinalizam ao leitor o que ainda não está dito. Em breve, a própria narradora será confrontada com a realidade, ao se mudar do centro da cidade para a periferia, lugar onde encontra lixo e outros dejetos abandonados e que em nada coincide com a casa fantasiada em seus desenhos e desejos infantis.

A narradora enfatiza que a cor do telhado na verdade não importava, já que desejava de fato a vida que se vivia dentro desse lar, com pais que preparam bolos aos domingos, com o retorno garantido do pai para o jantar, animais de estimação, enfim, uma vida sem sombras: "Me pergunto como podemos nos entender tão mal; ou se, ao contrário ela se obriga a acreditar que meu único sonho, o meu, está feito de jardim e cor vermelha". ${ }^{31}$

Essa primeira mudança do centro, onde vivia ao lado dos avós maternos, para a casa às margens da cidade, marca sua passagem da legalidade à clandestinidade, a partir da qual ela se esforçará para entender as regras do jogo: "Meu pai e minha mãe escondem aí em cima jornais e armas, mas eu não devo dizer nada. As pessoas não sabem que a nós, somente a nós, nos forçaram a entrar em guerra. Não entenderiam. Pelo menos não por enquanto". ${ }^{32}$

A partir da altura de seus sete anos, a menina tem como responsabilidade não delatar os pais e seus companheiros, como havia feito um bebê cuja história a mãe conta para que fique clara a importância de não falar. As pessoas não seriam capazes de entender a situação, mas ela se convence de que compreende - "Mas meu caso, claro, é totalmente diferente. Já sou grande, tenho sete anos mas todo mundo me diz que falo e penso como uma pessoa mais velha"133 - e se arma de uma coragem que as crianças não deveriam se preocupar em ter:

Me explicaram tudo. Eu entendi e vou obedecer. Não vou dizer nada. Nem que venham também a nossa casa e me machuquem. Nem que me torçam o braço

\footnotetext{
${ }^{29}$ Em espanhol: "desde la altura de la niña que fui". ALCOBA, Laura. La casa de los conejos. Op. cit., p. 12.

30 Em espanhol "Ahora, ¿ves?, nosotros también tendremos una casa con tejas rojas y un jardín. Como querías". Ibidem, p. 13.

${ }^{31} \mathrm{Em}$ espanhol: "Me pregunto cómo hemos podido nos entender tan mal; o si en cambio ella se obliga a creer que mi único sueño, el mío, está hecho de jardín y color rojo". Ibidem, p. 14.

32 Em espanhol: "Mi padre y mi madre esconden ahí arriba periódicos y armas, pero yo no debo decir nada. La gente no sabe que a nosotros, solo a nosotros, nos han forzado a entrar en guerra. No lo entenderían. No por el momento, al menos." ALCOBA, Laura. La casa de los conejos. Op. cit., p. 16-17.

${ }^{33} \mathrm{Em}$ espanhol: "Pero mi caso, claro, es totalmente diferente. Yo ya soy grande, tengo siete años pero todo el mundo me dice que hablo y razono como una persona mayor." ALCOBA, Laura. La casa de los conejos. Op. cit., p. 17.
} 
ou me queimem com o ferro de passar. Nem que me cravem preguinhos nos joelhos. Eu, eu compreendi até que ponto calar é importante. ${ }^{34}$

Podemos perceber como a pontuação contribui para construir a típica resolução das crianças. Em sua demonstração de valor, cada fala-ato de resistência imaginária deve ter seu próprio lugar, encontrado nas pausas entre um e outro.

O silêncio, representado aqui pelo uso do verbo "calar", atravessará toda a narrativa e se refletirá na relação que Laura mantém com a língua materna e com o francês. Em El azul de las abejas, a narradora se prepara para o exílio e reencontro com a mãe, quase três anos depois de se separarem, pouco antes do Golpe de Estado (1976). Neste livro, o leitor acompanha o encantamento e a obsessão despertados pela língua francesa, com suas vogais mudas, que estão e não-estão ao mesmo tempo. O francês é a língua na qual Alcoba escreve todas as suas obras literárias, e que permitiu, segundo a própria autora, em entrevista a Anne Diatkine, voltar ao passado traumático - "A língua francesa me permitiu sondar o silêncio e me livrar dele" ${ }^{\prime 35}$ - protegida pela autotradução que opera ao escrever na língua de acolhida e se distanciar da língua na qual aprendeu a emudecer.

Voltemos ao silêncio, que na verdade se apresenta sobretudo sob a face do silenciamento, já que na narrativa trata-se mormente de um não poder dizer. A respeito dessa questão, vale a pena mencionar o livro de Eni Orlandi, intitulado As formas do silêncio, no qual a autora defende que o silêncio não indica uma falta, mas um horizonte, ou seja, ele significa, funda sentidos: "O silêncio do sentido torna presente não só a iminência do não-dito, mas o indizível da presença: do sujeito e do sentido". ${ }^{36}$ Orlandi distingue o que denomina "silêncio constitutivo" do chamado "silêncio local", do qual a censura seria um exemplo. Com a censura, isto é, com a prática do silenciamento, instaura-se um jogo de relações de força em que há um limite, dentro do dizível, para aquilo que não pode ser dito quando se fala. Nas palavras da autora: "A censura joga com o poder-dizer impondo um certo silêncio". ${ }^{37}$

É assim que a narradora de La casa de los conejos "reconhece" que não pode mencionar as armas e os jornais ou, depois de se mudar para a casa dos coelhos e de o pai já ter sido preso, não pode revelar o próprio nome para a vizinha, nem fazer qualquer menção às visitas que faz ao pai na prisão.

\footnotetext{
${ }^{34}$ Em espanhol: "A mí ya me lo explicaron todo. Yo he comprendido y voy a obedecer. No voy a decir nada. Ni aunque vengan a casa y me hagan daño. Ni aunque me retuerzan en brazo o me quemen con la plancha. Ni aunque me claven clavitos en las rodillas. Yo, yo he comprendido hasta qué punto callar es importante". ALCOBA, Laura. La casa de los conejos. Op. cit., p. 18.

${ }^{35}$ No original: "La langue française m'a permis de sonder le silence et m'em défaire". DIATKINE, Anne. Le blocage espagnol de Laura Alcoba. Publicado em: 4 ago. 2014. Disponível em: https://next.liberation.fr/livres/2014/08/04/le-blocage-espagnol-de-laura-alcoba_1075473. Acesso em: 20 nov. 2018.

${ }^{36}$ ORLANDI, Eni P. As formas do silêncio: no movimento dos sentidos. Campinas, SP: Ed. Unicamp, 2007, p. 70.

${ }^{37}$ Ibidem, p. 85.
} 
Parece haver entre as crianças um "pacto" de silêncio, como podemos observar no trecho em que a narradora relata o encontro com os filhos de um casal que as acolhera por alguns dias:

Eu brinco um pouco com eles, brincadeiras às quais não estou nem um pouco acostumada. Entre nós, jamais falamos do que está acontecendo, nem da clandestinidade - será que explicaram a eles como fizeram comigo? - nem da guerra na qual nos obrigaram a entrar $[\ldots]$ Também não falamos do medo. ${ }^{38}$

Se, por um lado, o não-dizer pode ser lido como cumplicidade, ainda que sob o signo do medo, outros momentos revelam apenas a angústia: "Faz-se um silêncio incômodo. Perturbador" / "O silêncio pesava como algo sólido". ${ }^{39}$ À medida que a palavra "medo" começa a se repetir na narrativa, a menção aos silêncios aumenta, denunciando ao leitor a crescente repressão e os modos específicos de vivência de uma criança em meio a uma situação inapreensível.

Em El azul de las abejas o silêncio está presente sobretudo em dois pontos: um deles é a recusa em atender a um pedido do pai, com o qual a narradora começa uma profícua correspondência após sua partida para a França. Na própria correspondência há silenciamentos, tendo em vista que toda carta tinha de passar por "criteriosa" análise dos agentes da prisão onde se encontrava o pai. Entretanto, em uma das cartas ele pede à filha que envie uma foto, solicitação que a filha ignora, silencia, criando um conflito que perdura até o último capítulo. Nele, a narradora relaciona o envio da foto ao fato de finalmente ter conseguido pensar em francês, através da metáfora dos encanamentos - tuberías - que perpassa todo o livro: "Não sei que relação haveria isso com meus encanamentos, mas sei que só depois de ter conseguido deslizar-me por eles pude escolher a quinta foto que ele tanto desejava". ${ }^{40}$

Ao remeter a foto, a voz da narradora adulta irrompe para tratar de entender, ao menos hipoteticamente, as razões da recusa silenciosa:

Ainda hoje me recordo colocando a foto no envelope sem mais nem menos, sem dar explicações para aquela espera tão longa nem me desculpar por meu persistente silêncio. Como se todo esse tempo tivesse sido lógico e necessário para que a foto aparecesse. ${ }^{41}$

\footnotetext{
${ }^{38}$ Em espanhol: "Yo juego un poco con ellos, juegos a los que no estoy nada habituada. Entre nosotros, jamás hablamos de lo que está pasando, ni de la clandestinidad - ¿se lo habrán explicado a ellos, como me explicaron a mí? - ni de la guerra en la que nos obligaron a entrar [...] No hablamos del miedo tampoco." ALCOBA, Laura. La casa de los conejos. Op. cit., p. 42.

39 Em espanhol:" Se hace un silencio incómodo. Perturbador." / "El silencio pesaba como algo sólido." Ibidem, p. $120 ; 121$.

40 Em espanhol: "No sé qué relación habrá tenido esto con mis tuberías, pero sé que solo después de haber logrado deslizarme por ellas pude elegir la quinta foto que él tanto me reclamaba." ALCOBA, Laura. El azul de las abejas. Trad.: Leopoldo Brizuela. Buenos Aires: Edhasa, 2014, p. 120.

${ }^{41}$ Em espanhol: "Todavía hoy me recuerdo deslizándola en el sobre como si nada, sin dar explicaciones por aquella espera tan larga ni disculparme por mi persistente silencio. Como si todo ese tiempo hubiera sido lógico y necesario para que la foto apareciera." Ibidem, p. 121.
} 
Outro ponto em que o silêncio se faz presente em El azul de las abejas é na relação da protagonista com o francês, cujas vogais mudas ela contrapõe ao barulho excessivo do castelhano:

Amei aquela primeira e muda como todas as que vieram depois. Mas mais que isso, em realidade. CreAio que só pelo fato de existirem, já as admiro. Às vezes chego a entrever por que as [vogais] e mudas me emocionam tão profundamente. Ser ao mesmo tempo indispensáveis e silenciosas: eis aqui algo que não podem fazer as vogais em castelhano, algo que não conseguirão fazer jamais. ${ }^{42}$

A comparação da língua materna com o francês, a partir da qualidade das vogais de significarem em silêncio, remete ao que Eni Orlandi afirma sobre a prática da escrita como um espaço intermediário no qual o sujeito evoca o silêncio dos outros sentidos ou os outros sentidos do silêncio, fazendo com que apareçam.

A menina fica obcecada pela discrição das vogais francesas, cujo desejo de apropriação a acompanhará até o fim do livro, numa relação de contraposição ao espanhol, cujo acento denunciava seu "lugar" de refugiada perante os companheiros de escola. A censura foi introjetada a ponto de ela ter pesadelos em que se via nua e logo relacionar à sensação de exposição vivenciada quando, na tentativa de falar francês, sentia que o ruído da língua materna estava presente. Era preciso silenciar a língua em que seu pai fora preso, em que amigos dos pais foram desaparecidos, assassinados, esquecer a origem, apagar as marcas do estrangeirismo. O espanhol figura como a língua ruidosa na qual a menina - recordemos $L a$ casa de los conejos - aprendeu a importância e urgência de calar, pois o silêncio salvava vidas, ao passo que as palavras poderiam provocar o desaparecimento, uma cruel forma de silenciamento. O francês representa, poderíamos pensar, o idioma através de cujos meandros silenciosos ela pôde encontrar finalmente uma entrada para a escavação dolorosa da memória.

Toda intrusão nesse sentido foi combatida de maneira visceral, para que somente o francês, com suas vogais escondidas detrás do nariz, pudesse ser canal para sua voz e, anos mais tarde, da adulta que finalmente empreende um esforço de memória e escreve como ato de rememoração e tentativa de olvido. No entanto, essa intromissão da língua materna ocorre por meio de alguns termos e frases que fazem sua irrupção na narrativa, apesar do desejo da menina-narradora. Destacados em itálico na edição original francesa, temos, por exemplo, o título de um dos capítulos - Señorita - e frases evocadas de outras personagens - Llegamos, por fin! -, entre outros.

Vale a pena citar um dos fragmentos em que Orlandi discorre sobre a relação do processo de escrita com o silêncio:

Escrever é uma relação particular com o silêncio. A escrita permite o distanciamento da vida cotidiana, a suspensão dos acontecimentos. Ela permite

\footnotetext{
42 Em espanhol: "Amé aquella primera e muda como todas las que vinieron después. Pero más que eso, en realidad. Creo que a todas, por el solo hecho de existir, las admiro. A veces llego a entrever por qué las e mudas me emocionan tan profundamente. Ser a la vez indispensables y silenciosas: he ahí algo que no pueden hacer las vocales en castellano, algo que no lograrán jamás." ALCOBA, Laura. El azul de las abejas. Op. cit., p. 71.
} 
que se signifique em silêncio. Assim, há autorreferencialidade sem que haja intervenções da situação ordinária (a censura) de vida: o autor escreve para significar (a) ele mesmo. ${ }^{43}$

Na escrita, o silêncio resiste em sua multiplicidade de sentidos, o que parece ir ao encontro do que Arfuch afirma sobre a perspectiva narrativa e sua dimensão ética. Segundo ela, ao tratar de recompor, dar forma à história pessoal, lidamos com uma dimensão terapêutica, que responderia à necessidade do dizer, do narrar, mas também há o caráter ético, uma vez que a escrita restauraria um fio rompido da escuta e, por conseguinte, da responsabilidade com o outro. Além disso, permite, "começar a abrir o caminho que leva do individual ao coletivo, a memória como um passo obrigatório para a história. ${ }^{44}$

Primeiro silenciar, depois narrar, inclusive os silêncios, é também um caminho para resistir, para iluminar os sulcos que a experiência imprime e que a adulta olha, à distância do exílio, da língua, do tempo na distância terapêutica e propedêutica da língua monumento e acolhimento: o francês.

Lançado em 2017, La danse de l'araignée, traduzido ao espanhol por Mirta Rosenberg e Gastón Navarro sob o título La danza de la araña (2017), apresenta a narradora com cerca de 12 anos. Nele encontramos, na forma de epígrafe, uma citação de Gérard de Nerval, importante escritor francês do século XIX: "Persigo uma imagem, nada mais". ${ }^{45}$ Essa epígrafe nos levaria a um longo passeio pelos bosques da citação, mas atenhamo-nos, neste trabalho, a pensar o que ela pode nos dizer sobre a obra de Alcoba: que imagem persegue a narradora? Qual seria a imagem justa, portadora de justiça e justeza? É possível encontrar uma imagem na qual o passado revele o que nele há de presente ou o que dele atravessou as miríades do tempo, do exílio, da separação? Narrar, em Alcoba, é perseguir uma imagem, nada mais. Não se trata tanto de encontrá-la, mas de sua busca, de escrever a busca, fazê-la luzir mesmo em sua ausência.

Neste livro, a narradora abre o relato com a descrição do bairro para onde se mudara com a mãe e Amalia, antiga companheira de militância que também se refugiara na França, traçando linhas imaginárias para situar o pai, que permanecia no outro hemisfério, na Unidade Nove de La Plata - "Papai se encontra no extremo sul - em alguma parte da linha invisível". ${ }^{46}$ Ela continua a se corresponder com ele, embora o pai se queixe de um distanciamento, refletido na observação de que a filha estaria lendo menos. A "presença" paterna se dava por meio das cartas e do que, através dos livros que ambos liam juntos, podiam compartilhar apesar dos milhares de quilômetros de distância.

\footnotetext{
43 ORLANDI, Eni P. As formas do silêncio... Op. cit., p. 83.

44 No original: "comenzar a franquear el camino de lo individual a lo colectivo, la memoria como paso obligado hacia la historia." ARFUCH, Leonor. La vida narrada... Op. cit., posição 968-970.

45 Umberto Eco faz uma minuciosa leitura do romance Sylvie, do qual foi retirada a citação. Cf.: ECO, Umberto. Seis passeios pelos bosques da ficção. São Paulo: Companhia das Letras, 1994.

${ }^{46}$ Em espanhol: "Papá se encuentra al extremo sur-en alguna parte de la línea invisible". ALCOBA, Laura. La danza de la araña. Trad.: Mirta Rosenberg; Gastón Navarro. Buenos Aires: Edhasa, 2017, p. 13.
} 
Logo no segundo capítulo, a narradora menciona uma história contada pelo pai e que a impressionara a ponto de eles passarem meses girando ao redor do tema. Um homem tem uma tarântula de estimação que mantém em uma gaiola e, segundo narra o pai, cada vez que retorna do trabalho, ela começa a "dançar". O homem então abre a gaiola e a acaricia por alguns instantes: "Seus encontros são sempre silenciosos, escreve papai" ${ }^{47}$ Podemos ler nesta pequena narrativa que dá título ao livro, uma referência à relação entre a protagonista e o pai, cujas cartas seriam como o ritual entre a aranha e seu dono. No encontro provisório e silencioso propiciado pelas cartas, pleno de sentidos, é como se as grades que o cercavam se desfizessem e por um tempo a liberdade o acariciasse também.

Vale mencionar que o último capítulo se intitula, não por acaso, "Araña", e nele a narradora conta como recebeu a notícia da libertação do pai e como se deu o reencontro de ambos no aeroporto. Duas imagens marcam esse momento: a primeira é a dos tubos, que ela havia visto pela primeira vez quando chegara à França anos antes e que, como vimos com El azul de las abejas, a menina relacionava ao idioma e os caminhos para acessá-lo. A essa imagem a narradora relaciona a da aranha:

Esses tubos parecem tentáculos, já sei. Ou as patas em desordem de uma imensa aranha. Pode ser que papai já esteja avançando por uma dessas patas. Neste mesmo instante, possivelmente haja viajantes passando por cima de sua cabeça, no tubo que lhes corresponde [...] Papai pensará em saudar seus camaradas de órbita com um gesto, mesmo que seja uma pequena saudação, quando passa ao lado de um deles? Ou olhará para frente, dizendo-se que já é hora de sair da tarântula? ${ }^{48}$

Há muito o que ler nesse excerto, de rara riqueza poética e repleto de significados, alusões ao passado, mas também ao porvir anunciado pela pergunta imaginada pela narradora: seria tempo de sair da tarântula? De seguir em busca de novas imagens, metáforas para iluminar outros recônditos?

Gostaríamos de mencionar ainda duas situações que parecem confluir para a ideia expressa no fragmento citado: a primeira ocorre no capítulo "La muñeca de plástico", quando a narradora e sua amiga Fatou são seguidas por um desconhecido no trajeto da escola para a casa. Após se sentir mais segura, a protagonista vai para o próprio edifício, mas o homem a chama e em seguida começa a fazer gestos que ela não consegue compreender de todo e que, portanto, associa ao mundo infantil: ele toca uma boneca calva e vermelha até que ela chora. O leitor percebe claramente a alusão à masturbação, mas aqui o que realmente interessa dessa imagem é o que ocorre depois:

\footnotetext{
47 Em espanhol: "Sus encuentros son siempre silenciosos, escribe papá". ALCOBA, Laura. La danza de la araña. Op. cit., p. 19.

48 Em espanhol: "Esos tubos parecen tentáculos, ya lo sé. O las patas en desorden de una inmensa araña. Puede ser que papá ya esté avanzando adentro de una de esas patas. En este mismo instante, posiblemente haya viajeros pasando por encima de su cabeza, en el tubo que les corresponde [...] ¿Papá pensará en hacerles un gesto con la mano a sus camaradas de órbita, aunque sea un pequeño saludo, cuando pasa al lado de alguno de ellos? O mirará derecho, hacia adelante, diciéndose que ya es hora de salir de la tarántula?" Idem.
} 
Por sorte, recupero minha voz. E começo a gritar. Como jamais o fiz. Finalmente consigo. Grito pela boneca à qual arrancaram o cabelo. E por todo o resto. Grito também por tudo o que ocorreu antes da Capsulerie. Grito por todas as vezes em que me vi em sonhos, correndo sem avançar, incapaz de emitir um som, afundando mais profundamente na areia à medida em que agitava meus pés. Grito, não paro de gritar, nunca tinha gritado assim. Ignorava até que ponto podia ser um alívio. ${ }^{49}$

O grito silencioso que nos alcança no presente da leitura, essa voz que, mesmo assustada, finalmente encontra caminho para se fazer ouvir, é também a da memória, dos traços dolorosos convertidos em narrativa. Escrever é dar o grito. Ler pode ser uma das formas de ouvi-lo, mesmo que ouvir signifique receber os ecos de um passado que parece distante, alheio ao correr dos dias. As imagens que persistem, apesar do trabalho do esquecimento, devem ser perseguidas em sua rasura e em sua ranhura porque não é a totalidade do monumento que tem a força para traduzir a ferida do trauma, mas os restos presentificados do passado.

No capítulo intitulado "El adversário invisible", a narradora nos relata uma história que Amalia havia contado já pela quarta ou quinta vez e cuja recorrência, em lugar de aborrecê-la, na verdade a deixava fascinada. Trata-se de como sucedera a morte de Mariana, militante e namorada de Paco, ambos amigos de Amalia. Mariana e outros militantes aguardavam a chegada do rapaz, que, como sempre costumava ocorrer, estava atrasado. Alguém bate à porta e a moça percebe que "iam buscá-los". Mariana não diz quem seriam aqueles que ali estavam - observamos aqui o silenciamento advindo do temor, ao qual se oporá o silêncioresistência que segue depois. Segundo Amalia, Mariana estava ciente de que não falaria, mas também conhecia as consequências de se calar; por isso abriu a janela e, diante de Paco, que se aproximava da casa, saltou para a morte:

A sequência foi assim: passos no corredor, golpes na porta, porta derrubada, Paco que aparece na esquina, e imediatamente depois Mariana que sorri e que salta. Tudo isso veio encadeado, sem pausa, nem vacilação, como em um movimento contínuo, e Paco a viu perfeitamente, estava na calçada em frente, a poucos metros dela... 50

Dias depois, conta essa outra narradora a quem a protagonista cede a voz, quando estavam juntos em uma outra casa, Paco saiu de seu mutismo quase completo para perguntar a ninguém em particular: "Mas quanto tempo leva um corpo para cair do quinto andar?". ${ }^{51} \mathrm{~A}$ pergunta se repetiu inúmeras vezes nos dias que se seguiram juntamente com a ideia fixa,

${ }^{49} \mathrm{Em}$ espanhol: "Por suerte, termino por encontrar mi voz. Y me pongo a gritar. Como jamás lo he hecho. Finalmente, lo logro. Grito por la muñeca a la que le arrancaron el pelo. Y por todo lo demás. Grito también por lo que ocurrió antes de la Capsulerie. Grito por todas las veces que me he visto en sueños, corriendo sin avanzar, incapaz de emitir un sonido, hundiéndome más profundamente en la arena a medida que mis pies agitaban. Grito, no paro de gritar, nunca había gritado así. Ignoraba hasta qué punto podía ser un alivio." ALCOBA, Laura. La danza de la araña. Op. cit., p. 85.

${ }^{50} \mathrm{Em}$ espanhol: "La secuencia fue así: pasos en el corredor, golpes en la puerta, puerta derribada, Paco que aparece en la esquina, e inmediatamente después Mariana que sonríe y que salta. Todo eso vino encadenado, sin pausa, ni vacilación, como en un movimiento continuo. Y Paco la vio perfectamente, estaba en la vereda de enfrente, apenas a unos metros de ella..." Ibidem, p. 61.

${ }^{51}$ Em espanhol: "¿Pero cuánto tiempo tarda un cuerpo en caer del quinto piso?" Ibidem, p. 63. 
relata Amalia, de que "depois do sorriso e do salto, [Paco] viu o corpo de Mariana no ar, perfeitamente imóvel. É possível que por um instante tenha deixado de cair?"152

A insistência em ouvir, apesar de conhecer cada passo da narrativa de Amalia, assim como a pergunta de Paco, que congelara em sua mente a imagem de Mariana instantes antes de tocar o chão e morrer, leva-nos novamente à epígrafe: há imagens que perseguimos e há imagens que nos perseguem. Escrever sobre o trauma é perseguir imagens, como já afirmamos, é percorrer o caminho que leva sempre à mesma incompreensão, mas é também tentar se livrar delas: entregá-las a outro. No início de La casa de los conejos, na já citada apresentação, Alcoba declara: "se por fim faço todo esse esforço de memória para falar da Argentina dos Montoneros, da ditadura e do terror, a partir da altura da menina que fui, não é tanto para recordar como para ver se consigo, no fim das contas, de uma vez por todas, esquecer um pouco". 53

Escreve-se para esquecer, afirma a autora, mas para isso é preciso, retomando suas palavras, fazer um esforço de memória, isto é, recordar, tocar com a fragilidade que implica [re]viver o trauma, o "silêncio oco/o silêncio soco" dos que vivem a espera e à espera. Escrever talvez seja, ao fim e ao cabo, uma tentativa de fazer vir a "pergunta que nunca virá".

Conforme afirma Arfuch acerca das relações entre infância e memória, ambas parecem "enredar-se em uma relação particular, na qual a imagem evocada se plasma no presente da enunciação trazendo consigo uma carga afetiva que o transfigura: como toda memória, é sempre presente" ${ }^{54}$

As palavras finais de La casa de los conejos podem nos ajudar a pensar sobre a proposição de Arfuch. Vejamos: "Clara Anahí vive em alguma parte. Ela leva sem dúvida outro nome. Ignora provavelmente quem foram seus pais e como é que morreram. Mas estou segura, Diana, que tem seu sorriso, sua força, sua beleza. Isso, também, é uma evidência excessiva". ${ }^{55}$ Ao recobrar a infância, o medo, o silenciamento, as descobertas, os vazios, para "esquecer um pouco", Alcoba lança ao presente um rastro do passado ainda não resolvido. Faz-nos lembrar que Clara Anahí e milhares de outros homens e mulheres que um dia foram violentamente separados de seus familiares continuam em algum lugar e lugar nenhum, porquanto não sabem de sua própria história. O passado interroga o presente, atravessa a

\footnotetext{
52 Em espanhol: "después de la sonrisa y del salto, vio el cuerpo de Mariana en el aire, perfectamente inmóvil. ¿Es posible que por un instante haya dejado de caer?". ALCOBA, Laura. La danza de la araña. Op. cit., p. 63.

${ }^{53}$ Em espanhol: "si al fin hago este esfuerzo de memoria para hablar de la Argentina de los Montoneros, de la dictadura y del terror, desde la altura de la niña que fui, no es tanto por recordar como por ver si consigo, al cabo, de una vez, olvidar un poco". ALCOBA, Laura. La casa de los conejos. Op. cit., p. 12.

${ }^{54}$ No original: "Infancia y memoria parecen así enlazarse en una relación particular, donde la imagen evocada se plasma en el presente de la enunciación trayendo consigo una carga afectiva que lo transfigura: como toda memoria, es siempre presente." ARFUCH, Leonor. La vida narrada... Op. cit., posição 1176-1177.

55 Em espanhol: "Clara Anahí vive en alguna parte. Ella lleva sin duda otro nombre. Ignora probablemente quiénes fueron sus padres y cómo es que murieron. Pero estoy segura, Diana, que tiene tu sonrisa, tu fuerza, tu belleza. Eso, también, es una evidencia excesiva". ALCOBA, Laura. La casa de los conejos. Op. cit., p. 134.
} 
quietude das casas de cada mulher de quarenta e poucos anos cujo sorriso seja luminoso como o de Diana. Suspensa como o corpo de Mariana, congelada como aquela imagem, essa parte do passado nos interpela com toda a sua carga de dor.

Para finalizar, mas de forma algum fechar esta leitura, gostaríamos de retomar a citação de Georges Didi-Huberman acerca dos vaga-lumes. Para onde teriam ido os vagalumes, ou seja, a resistência representada por esses pequenos pontos luminosos em meio à escuridão? Não nos cabe aqui fazer uma análise do livro de que esta citação foi extraída Sobrevivência dos vaga-lumes -, mas apenas para contextualizar vale a pena uma breve explanação. Didi-Huberman parte da obra do escritor e cineasta italiano Pier Pasolini que, em dado momento, declara a morte dos vaga-lumes, daqueles "lampejos de inocência" frente à realidade abrumadora do fascismo. O que o pensador francês faz é defender, neste livro, a sobrevivência, embora sob outras formas, dessas pequenas fulgurações capazes de iluminar o presente.

Ao retomar a noção de indestrutível de Maurice Blanchot, que contém em si um aparente paradoxo no qual residiria sua força - o de que "o homem é indestrutível e que, no entanto, ele pode ser destruído"56 - o autor explica que essa noção está relacionada a uma maneira particular de entender o termo "sobrevivência". Em suas palavras, trata-se da "sobrevivência dos signos ou das imagens, quando a sobrevivência dos próprios protagonistas se encontra comprometida". ${ }^{57}$

Assim, segundo Didi-Huberman, "os vaga-lumes, depende apenas de nós não vê-los desaparecerem" e para tanto, é preciso aprender a olhar para além da luz ofuscante e excessiva em que estamos inundados. ${ }^{58}$ Devemos buscar "imagens-vaga-lumes", lampejos que nos alcançam, mas que é preciso saber enxergar. Nesse sentido, narrativas como a de Alcoba, que se lançam ao passado traumático da experiência pessoal e da petite histoire argentine, emitem, desse lugar inatual, sinais que podem ser lidos como práticas de resistência.

Perseguir uma imagem, nesse processo de escavação da memória, não garante justiça ao passado, aos que desapareceram, aos que permanecem sem saber quem são, mas aponta para o dever da busca. Nesse sentido, os relatos são testemunho de uma perseguição que visa a alcançar tanto a justiça como a justeza, conforme mostram as referências a documentos materiais e às formas imagéticas próprias do ato de rememoração. Os vazios interpelam aquele que lê e que também, como diante de um espelho, tenta escavar a própria história, na tentativa de chegar à imagem que se encaixa em seu próprio rosto.

A não-imagem de Clara Anahí que nos é legada, assim como a não-imagem que o leitor recebe da Foto do Jardim de Inverno, convocam-nos a continuar a nossa própria busca, a apurar o olhar e a audição para, nas ausências e nos silêncios, nos meandros da memória que

\footnotetext{
${ }^{56}$ BLANCHOT, Maurice apud DIDI-HUBERMAN, Georges. Sobrevivência dos vaga-lumes. Op. cit., p. 150.

${ }^{57}$ Idem.

${ }^{58}$ Ibidem, p. 154.
} 
não nos pertence porque o outro sempre nos constitui, tratar de ver ali a ferida. Ela é sempre nossa. 


\section{Referências Bibliográficas}

ALCOBA, Laura. El azul de las abejas. Buenos aires: Edhasa, 2014.

ALCOBA, Laura. La casa de los conejos. Trad.: Leopoldo Brizuela. Buenos Aires: Edhasa, 2014.

ALCOBA, Laura. La danza de la araña. Trad.: Mirta Rosenberg, Gastón Navarro. Buenos Aires: Edhasa, 2017.

ARFUCH, Leonor. La vida narrada. Memoria, subjetividad y política (Poliedros - Zona de crítica) (Spanish Edition, 2018). Ebook Kindle.

ARFUCH, Leonor. O espaço biográfico: dilemas da subjetividade contemporânea. Trad.: Paloma Vidal. Rio de Janeiro: EdUERJ, 2010.

AVELAR, Idelber. Alegorias da derrota: a finção pós-ditatorial e o trabalho do luto na América Latina. Trad.: Sandro Gouveia. Belo Horizonte: Ed. UFMG, 2003.

BARTHES, Roland. A câmara clara: nota sobre a fotografia. Trad.: Júlio Castañon Guimarães. Rio de Janeiro: Nova Fronteira, 2015.

DE MAN, Paul. La autobiografía como desfiguración. Suplemento Anthropos, Barcelona, Anthropos, n. 29, p. $113-118,1991$.

DIATKINE, Anne. Le blocage espagnol de Laura Alcoba. Publicado em: 4 ago. 2014. Disponível em: https://next.liberation.fr/livres/2014/08/04/le-blocage-espagnol-de-laura-alcoba_1075473. Acesso em: 20 nov. 2018.

DIDI-HUBERMAN, Georges. Sobrevivência dos vaga-lumes. Trad.: Vera Casa Nova; Márcia Arbex. Belo Horizonte: Ed. UFMG, 2011.

ECO, Umberto. Seis passeios pelos bosques da ficção. São Paulo: Companhia das Letras, 1994.

LEJEUNE, Philippe. O pacto autobiográfico. De Rousseau à internet. Org.: Jovita Maria Gerheim Noronha. Trad.: Jovita Maria Gerheim Noronha; Maria Inês Coimbra Guedes. Belo Horizonte: Ed. UFMG, 2008.

PRON, Patricio. O espírito dos meus pais continua a subir na chuva. Trad.: Gustavo Pacheco. São Paulo: Todavia, 2018.

SARMIENTO, Domingo Faustino. Facundo ó civilización i barbarie en las pampas argentinas. $3^{3}$ ed. Nova York: [s.n.], 1868. Versão digitalizada disponível em: http://www.cervantesvirtual.com/obra/facundo-ocivilizacion-i-barbarie-en-las-pampas-argentinas--0/. Acesso em: 31 jan. 2018.

SELIGMANN-SILVA, Márcio. Apresentação da questão: a literatura do trauma. In: SELIGMANN-SILVA, Márcio (org.). História, memória, literatura: o testemunho na Era das Catástrofes. Campinas, SP: Ed. Unicamp, 2003.

TONUS, Leonardo. Agora vai ser assim. São Paulo: Nós, 2018. 